\title{
Raynaud's disease
}

\author{
E C BURNS, D B DUNGER, AND M J DILLON
}

Hospital for Sick Children, Great Ormond Street, London

SUMMARY We report five children who presented with Raynaud's disease in whom we could find no clinical, haematological, or immunological evidence of a collagen disorder. Oral phenoxybenzamine proved useful for maintenance treatment in most, with infusions of prostacyclin, nitroprusside, and ketanserin during acute attacks.

Raynaud's syndrome indicates reversible, intermittent pallor or cyanosis, or both, of the fingers or toes in response to cold or stress, and is rare in childhood. In severe cases the ischaemia may lead to areas of infarction in the hands and feet. According to current nomenclature, the term Raynaud's disease describes idiopathic Raynaud's syndrome whereas the term Raynaud's phenomenon indicates that the condition is secondary to another disease. In childhood, Raynaud's phenomenon is generally associated with a collegen disorder and is more common than the idiopathic disease. ${ }^{1}$ The first description of Raynaud's disease in children was published in $1967,{ }^{2}$ although earlier adult series included patients whose symptoms began in childhood, ${ }^{34}$ and there have been a limited number of reports since. ${ }^{5-7}$

In adults with apparent Raynaud's disease, certain haematological and immunological parameters have been shown to be associated with the development of a collagen disorder, ${ }^{8}$ and a variety of drugs have recently been used with effect $;{ }^{9}$ but there remains little information about the prognosis and treatment in children. We describe five children with Raynaud's disease and discuss their investigations, treatment, and progress.

\section{Methods}

Platelet aggregation titres were determined using a method adapted from that of Penttinen and Myllyla. ${ }^{10}$ The aggregations seen with the patients' samples are expressed as titre $\times \log _{2}$ of control samples. 'Spontaneous' platelet aggregation was looked for in patients' platelet rich plasma that had been stirred without the addition of plateiet agonists in a Payton Dual Channel aggregometer. The findings were confirmed by examining an aliquot microscopically.
The thermography was carried out by Dr E D Cook. Abnormal vasospasm was detected using infrared thermography after mild cold stress, and arterial photoplethysmography was used to obtain further quantitative assessment of digital circulation. ${ }^{11} 12$

\section{Case Reports}

\section{Patient 1}

In January 1980 a 7 year old girl presented with a two year history of winter chilblains affecting her right foot predominantly and a month's history of cold right toes with the development of areas of necrosis on the tips of the first two. She is of Asian origin and was born in this country after an uneventful pregnancy, and a delivery at term by caesarean section because of breech presentation. Her birthweight was $2.34 \mathrm{~kg}$. There was nothing of importance in her past or family medical history. She was short with a height and weight below the 3rd centile. She had normal peripheral pulses but some limb asymmetry, her right arm being larger than her left and her left leg longer than her right by $4.0 \mathrm{cms}$. She had a single café au lait spot. Her skeletal survey showed various spinal anomalies including spinal dysraphism of the sixth and seventh cervical vertebrae and partial fusion of these vertebrae on the right. In addition there was partial fusion on the left of the fifth and sixth thoracic vertebrae. A myelogram was normal. The combination of the spinal anomalies and asymmetrical limbs suggested a diagnosis of neurofibromatosis but there was no other evidence of the condition.

Thermography showed that she had adequate limb vascularisation and there was no evidence of arterio-venous shunting. Cold stress produced an abnormal vascular response consistent with Raynaud's syndrome. The vasoconstriction of the digital arteries was most noticeable in the right foot, 
where the pressure drop between the posterior tibial and digital vessels of the first toe was of the order of $20 \mathrm{~mm} \mathrm{Hg}$.

\section{Patient 2}

In February 1982 a 9 year old boy presented with a three month history of Raynaud's syndrome affecting his feet predominantly. Three weeks previously he had developed necrotic areas on the tips of the right second and left fourth and fifth toes. In other respects he was healthy and there was nothing of relevance in his birth or past history. He was born in the UK. His father is Asian and remembers suffering from Raynaud's syndrome during his first few winters in Europe; mother is Caucasian. His sister later presented with Raynaud's syndrome (patient 4).

Physical examination was unremarkable apart from the cold hands and feet and necrotic toe lesions. His pulses were normal. Thermography showed normal limb vasculature but cold stress initiated vasospasm in the digits and toes.

\section{Patient 3}

This 9 year old boy presented in July 1982 with a three year history of Raynaud's syndrome affecting his hands and feet in the winter months. During cold weather small necrotic areas would occur on the tips of his fingers and toes. His birth history and past history were normal. His parents are Asian; he was born in this country but lived in India from 18 months to 5 years of age. He had no symptoms of Raynaud's syndrome while in India. His parents and two siblings are healthy. Examination was normal apart from his cold hands and feet, ulcer scars on his finger tips, and a left cataract (secondary to previous non-accidental injury). Thermography showed changes of Raynaud's syndrome with a fall of 40 to $65 \mathrm{~mm} \mathrm{Hg}$ between the main vessels of the upper and lower limbs and the digital arteries indicating severe vasoconstriction in the small arteries.

\section{Patient 4}

This 11 year old girl, the sister of patient 2, presented in February 1983 with a history of Raynaud's syndrome during the previous two months, she had also developed patches of necrosis on the tips of her first four right toes but she was otherwise healthy and there was nothing of importance in her birth or past medical history. Her father is Asian and her mother Caucasian. Examination showed no abnormality apart from her cool hands and feet and toe ulcers. Thermography showed changes typical of Raynaud's syndrome.

\section{Patient 5}

In October 1983, a 5 year old Caucasian boy presented with a 10 day history of pain and blueness of his fingers and of necrosis of his right fourth and left second and fourth finger tips. There was no known history of cold exposure. There was nothing of importance in his birth, past, or family medical history except that a number of father's relatives had suffered from lymphomas. On examination his hands were noted to be cool, he had small necrotic lesions on his finger tips and his pulses were normal; no other abnormality was noted. Thermography showed normal pressures in the palmar arches but a gradual fall off along the digital vessels; cold stress initiated vasospasm and the limb vasculature was normal.

Investigations. All patients had normal haematological indices on hospital admission and at follow up. Their indirect Coombs' tests, cold agglutinins, cryoglobulins, plasma fibrinogen, and plasma viscosity were estimated on admission and were normal apart from three who had slightly low plasma viscosity values (patient $2,1.09 \mathrm{cp}$; patient $3,1.22$ $\mathrm{cp}$; patient $4,1.3 \mathrm{cp}$; normal range 1.5 to $1.75 \mathrm{cp}$ ) and two whose plasma fibrinogen concentrations were low (patient $2,1.8 \mathrm{~g} / \mathrm{l}$; patient $3,1.2 \mathrm{~g} / \mathrm{l}$; normal range 2 to $4 \mathrm{~g} / \mathrm{l})$. No patient had an abnormality of immunoglobulins and all had negative rheumatoid factors, antinuclear factors, and autoantibody screens. All children had normal $\mathrm{C} 3$ values but four had slightly raised values of C4 (patient $2,94 \mathrm{mg} / 100$ $\mathrm{ml}$; patient 3, $152 \mathrm{mg} / 100 \mathrm{ml}$; patient $4,94 \mathrm{mg} / 100$ $\mathrm{ml}$; and patient $5,92 \mathrm{mg} / 100 \mathrm{ml}$ : normal range 20 to $65 \mathrm{mg} / 100 \mathrm{ml})$. Four patients had raised platelet aggregation titres. In three (patients 2, 3, and $4, \times 3$ $\log _{2}$ control) this test was performed while they were asymptomatic and was mildly abnormal. In the fourth (patient $1, \times 6 \log _{2}$ control) it was raised during an acute attack, but when she was asymptomatic it was normal. In only one patient (patient 1) was spontaneous platelet aggregation noted and this was during an acute attack.

Treatment and progress. Details of the various drugs used in the treatment of these children are given in the Table. Three of the children (patients 2, 3, and 4) responded to oral phenoxybenzamine. Their necrotic lesions slowly healed and they became asymptomatic. They have remained on treatment for 29,25 , and 18 months respectively, and are well.

The first patient (patient 1) also responded to oral phenoxybenzamine initially, and her hands and feet became warmer and her toe lesions healed. She remained on phenoxybenzamine for three years until she went to India on holiday and the drug was 
Table Details of treatments used in patients with Raynaud's disease

\begin{tabular}{|c|c|c|c|}
\hline Drug & Dose & Frequency & Route \\
\hline Phenoxybenzamine & $\begin{array}{c}0.25-1.0 \mathrm{mg} / \mathrm{kg} \\
\text { per day }\end{array}$ & 8 hourly & Oral \\
\hline Ketanserin & $3 \mathrm{mg} / \mathrm{kg}$ per day & 8 hourly & Oral \\
\hline $\begin{array}{l}\text { Nifedipine } \\
\text { Salicylate }\end{array}$ & $1 \mathrm{mg} / \mathrm{kg}$ per day & 6 hourly & Oral \\
\hline & alternate day & - & Oral \\
\hline $\begin{array}{l}\text { Dipyridamole } \\
\text { Prostacyclin }\end{array}$ & $\begin{array}{l}5 \mathrm{mg} / \mathrm{kg} \text { per day } \\
4-20 \mathrm{ng} / \mathrm{kg}\end{array}$ & 8 hourly & Oral \\
\hline & per $\min$ & - & iv \\
\hline Nitroprusside & $\begin{array}{c}0.5-5.0 \mu \mathrm{g} / \mathrm{kg} \\
\text { per min }\end{array}$ & - & iv \\
\hline $\begin{array}{l}\text { Ketanserin } \\
\text { CLI15,347 }\end{array}$ & $\begin{array}{l}0.2 \mathrm{mg} / \mathrm{kg} \text { per } \mathrm{hr} \\
500 \mu \mathrm{g}\end{array}$ & $\overline{12}$ hourly & $\begin{array}{l}\text { iv } \\
\text { Trans- } \\
\text { dermal }\end{array}$ \\
\hline
\end{tabular}

stopped. On her return to the UK she remained well, off treatment, until October 1983 when the tips of the second, third, fourth, and fifth toes of her right foot became blue and swollen after dancing barefoot on a cold floor. The phenoxybenzamine was restarted but the toe lesions deteriorated. Improvement was noted during a short prostacyclin infusion (four hours) and was maintained during an infusion of nitroprusside (48 hours). Oral salicylates and dipyridamole were also given because her platelets showed mild spontaneous aggregation and her platelet aggregation titre on hospital admission was raised (although not subsequently). Her hands and feet became warmer and her toe lesions gradually healed. The antiplatelet treatment was continued for two months. She is now maintained on phenoxybenzamine and remains well 4.5 years after diagnosis.

Oral phenoxybenzamine was not effective in the acute management of the last patient (patient 5). Infusions of prostacyclin and nitroprusside produced transient clinical improvement, but a sustained response was only obtained with a combination of iv followed by oral ketanserin and oral nifedipine. Once the lesions had begun to heal he was started on transdermal prostaglandin analogue (CL115,347, Cyanamid-kindly provided by Dr E D Cook). Over the subsequent six months he was weaned off the oral medications and is now maintained on the prostaglandin analogue. Ten months after diagnosis, he remains well.

\section{Discussion}

These children all presented with Raynaud's syndrome of sufficient severity to cause ischaemic changes to their fingers or toes. In four the symptoms were precipitated by cold and in the fifth, the boy who was too young to give details of the history himself (patient 5), this also seemed likely. In retrospect, stress may have been a contributory precipitating factor in the child who later suffered a non-accidental injury (patient 3). Four of our patients are of Asian origin and developed symptoms of Raynaud's syndrome only while they were in the UK. We are not aware of any increased incidence of Raynaud's disease on the Indian subcontinent or among the Asian population of this country. Simple enquiries did not disclose that any ergot-containing medicines or foods had been used by the families of these children. Certain features of patient 1 suggest a diagnosis of neurofibromatosis. Involvement of the heart and aorta, renal, carotid, and other arteries may occur in that condition ${ }^{13}$ and Erickson et al described two sisters with neurofibromatosis and intracranial arterial occlusive disease. ${ }^{14}$ We, however, were unable to show any large vessel disease in our patient and as far as we are aware, neurofibromatosis has not been previously reported in association with Raynaud's syndrome.

Raynaud's syndrome is a well recognised presenting feature of collagen disorders in childhood, particularly mixed connective tissue disease, but it is generally not an isolated symptom and serological evidence of the underlying disorder is usually found. From adult studies it seems unlikely that a patient with isolated Raynaud's syndrome will develop a collagenosis if there is no suggestion of this within 12 months of presentation. ${ }^{15}$ All but one of our patients have been followed up for longer than a year, none have developed clinical evidence of a collagen disorder, and their immunological studies remain normal, apart from four with high normal serum $\mathrm{C} 4$ value.

The presence of circulating immune complexes, spontaneous platelet aggregation, and fibrinolytic activity have been shown to correlate well with Raynaud's phenomenon secondary to a collagen disease in adults. ${ }^{8}$ Spontaneous platelet aggregation was observed in one of our patients (patient 1). She also had a raised platelet aggregation titre during an acute attack, although not subsequently. Three other children had slightly raised platelet aggregation titres, two had slightly low plasma fibrinogen concentrations, and three low plasma viscosity values. The latter observations contrast with the hyperfibrinogenaemia and raised viscosity values that have been reported in adults with Raynaud's phenomenon. The importance of the findings in the absence of evidence of a collagen disorder is unclear. It seems appropriate for our patients to be diagnosed as having Raynaud's disease at present, although they clearly require careful follow up and could develop a collagen disease later. 
The plethora of drugs used in Raynaud's disease ${ }^{i 6}$ is a reflection of the difficulties of treatment and of the limited understanding of the condition's pathophysiology. Raynaud himself considered the attacks to be due to excessive sympathetic activity ${ }^{17}$ whereas Lewis ${ }^{18}$ found that the digital vessels were unusually reactive to cold and attributed the condition to a local abnormality within the vessel wall. Recently Lafferty and colleagues proposed that Raynaud's disease occurs because of a fault in the local histaminergic vasodilating system, which is itself under sympathetic control. ${ }^{19}$ If this is so it would help to explain the conflicting theories of Raynaud and Lewis and some of the other findings in Raynaud's disease, such as the non-specific immunological changes, the platelet abnormalities, and the reduced prostacyclin synthesis. Histamine is known to play a central role in suppressing the immune response and is also partly responsible for liberating prostacyclin from the endothelium.

Vasodilators, either acting via the sympathetic nervous system as $\alpha$-adrenergic blockers or by directly relaxing smooth muscle, have proved useful in many patients with Raynaud's syndrome. Oral phenoxybenzamine was beneficial in four of our patients but in the acute stage of the illness did not appreciably help the two with the worst disease (patients 1 and 5). Both children were subsequently given infusions of prostacyclin and nitroprusside. These drugs are potent vasodilators and prostacyclin also inhibits platelet aggregation. Recently it has been suggested that decreased prostacyclin production by the vessel wall endothelium plays a part in the development of Raynaud's syndrome and studies in adults have shown that intravenous prostacyclin reduces the frequency and duration of ischaemic attacks. ${ }^{20}$ In our patients prostacyclin and nitroprusside seemed to be helpful and one is now being successfully managed with a transdermal prostaglandin analogue. Antiplatelet treatment has also been advocated in Raynaud's syndrome as there is evidence that immunologically mediated endothelial damage and platelet activation contribute to the vascular disease. ${ }^{21}$ Patient 1 received standard antiplatelet treatment (salicylates and dipyridamole) but it is unclear how much this affected her recovery as she was also given a nitroprusside infusion when these medications were introduced. Two other vasodilators, nifedipine and ketanserin, were used in patient 5 . The former is a calcium channel blocker and has been employed with varying degrees of success in adults with Raynaud's syndrome ${ }^{22}$ and the latter is a serotonin antagonist. ${ }^{23}$ Intravenous ketanserin was associated with considerable clinical improvement, but as the nifedipine was started while he was receiving ketan- serin it is difficult to comment on the effect of this drug. From the experience with our patients, oral phenoxybenzamine seems to be useful for maintenance treatment of Raynaud's disease, and in the doses employed was not associated with any adverse side effects. In an acute attack we would suggest that infusions of prostacyclin, nitroprusside, or ketanserin be considered.

We are grateful to Dr E D Cook of St Bartholomew's Hospital, London for carrying out the thermography and to Mr T Noakes of The Hospital for Sick Children, London for performing the platelet function tests. We thank Cyanamid for supplying the prostaglandin analogue.

\section{References}

1 Singsen BA, Bernstein BH, Kronreich HK, King KK. Mixed connective tissue in childhood. J Pediatr 1977;90:893-900.

2 Guntheroth WG, Morgan BC, Harbinson JA, Mullins GL. Raynaud's disease in children. Circulation 1967;36:724.9.

${ }^{3}$ Hines EA, Christensen NA. Raynaud's disease among men. JAMA 1945;129:1-4.

${ }^{4}$ Gifford RW, Hines EA. Raynaud's disease among women and girls. Circulation 1957;16:1012-21.

5 Sayre JW. Raynaud's disease presenting in a 5 month old male infant. Pediatrics 1973;52:412-5.

6 Powell KR. Raynaud's phenomenon preceding lymphocytic leukemia. J Pediatr 1973;82:539-40.

7 Jung LKL, Dent PB. Prognostic significance of Raynaud's phenomenon in children. Clin Pediatr 1983;22:22-5.

8 Kallenberg CGM, Vallenga E, Wonda AA, Hauwthe T. Platelet activation, fibrinolytic activity and circulating immune complexes in Raynaud's phenomenon. J Rheumatol 1982;9: 878-84.

9 Belch JJ, Sturrock RD. Raynaud's syndrome: Current trends. Br J Rheumatol 1983;22:50-5.

10 Penttinen K, Myllyla G. Interaction of human blood platelets, viruses and antibodies. I platelet aggregation test with micro equipment. Ann Med Exp Biol Fenn 1968;46:188-92.

1 Cook ED, Bowcock SA, Smith AT. Photoplethysmography of the distal pulp in the assessment of the vasospastic hand. Angiology 1985;(in press).

12 Challoner AVJ. Photoelectric plethysmography for estimating cutaneous blood flow. In: Rolfe $\mathrm{P}$, ed. Non-invasive physiological measurements. Vol 1. London: Academic Press, 1979: 125-51.

13 Rosenquist GC, Krovetz LJ, Haller, JA, Simon AL, Bannayan GA. Acquired right ventricular outflow obstruction in a child with neurofibromatosis. Am Heart J 1970;79:103-8.

14 Erickson RP, Woolliscroft J, Allen RT. Familial occurrence of intracranial arterial occlusive disease (moyamoya) in neurofibromatosis. Clin Genet 1980;18:191-6.

15 Blain A, Coller FA, Carver GB. Arbor A. Raynaud's disease. A study of criteria for prognosis. Surgery 1951;29:387-97.

16 Coffman JD. Vasodilator drugs in peripheral vascular disease. N Engl J Med 1979;300:713-7.

17 Raynaud M. On local asphyxia and symmetrical gangrene of the extremeties. London: New Sydenham Society, 1888.

18 Lewis T. Experiments relating to the peripheral mechanism involved in spasmodic arrest of the circulation in the fingers, a variety of Raynaud's disease. Heart 1929;15:7-100.

19 Lafferty K, De Trafford JC, Roberts VC. Cotton LT. On the nature of Raynaud's phenomenon: the role of histamine. Lancet 1983;ii:313-4 
${ }^{20}$ Belch JJF, Newman P, Drury JK, et al. Prentice CRM. Intermittent epoprostenol (prostacyclin) infusion in patients with Raynaud's syndrome. Lancet 1983;i:313-5.

21 Jayson MIV. Systemic sclerosis-a microvascular disorder? $J$ Roy Soc Med 1983;76:635-41.

22 Rodeheffer RJ, Rommer JA, Wigley F, Smith CR. Controlled double blind trial of nifedipine in the treatment of Raynaud's phenomenon. $N$ Engl J Med 1983;308:880-3.
${ }^{23}$ Roald OK, Seem E. Treatment of Raynaud's phenomenon with ketanserin in patients with connective tissue disorders. $\mathrm{Br} \mathrm{Med} \mathrm{J}$ 1984;289:577-9.

Correspondence to Dr M J Dillon, Hospital for Sick Children, Great Ormond Street, London WC1.

Received 24 January 1985

Fifty years ago

\section{Proceedings of the Eighth Annual General Meeting of the British Paediatric Association}

\section{Arch Dis Child 1935;10:208}

The punishment of children. Dr Hugh Ashby opened a discussion on this topic at $8.30 \mathrm{pm}$ on May 3rd 1935 .

'Any punishment that is given by an adult, he said, should be prompt and calculated to the intelligence of the child. Punishment thoughtlessly and haphazardly applied will not act as a deterrent, and too mild a punishment has no effect as this leads to the spoilt child who has only got to make a fuss and he gets all he wants. A simple practical threat, that a child knows can and will be carried out, is always effective. Punishment at boy's schools used to be too severe-this has now changed as masters have become more understanding and better teachers. The better the master the less punishment he has to administer. It is far better to reward good conduct than to punish bad conduct. This line of action has proved a great success even at an institution like Borstal. Any punishment that has to be administered must be distasteful to the boy and above all he must not be deprived of exercise. The old idea of making a boy write out so many lines should be given up and some form of exercise like drilling instead of playing games should be substituted. Corporal punishment should be reserved for very serious offences only'.

(Hugh Ashby was a founder member of the British Paediatric Association, and its President in 1949. Like his father, he was on the staff of the Royal Manchester Children's Hospital, and also of the Salford Royal Hospital. Donald Winnicott-paediatrician and child psychiatrist, was among others who took part in the subsequent discussion. His contribution, alas, was not recorded. PAMELA A DAVIES.) 